\title{
Adoptability of Lean Construction Techniques in Pakistan's Construction Industry
}

\author{
Aftab Hameed Memon ${ }^{\mathrm{a} *}$, Muhammad Akram Akhund ${ }^{\mathrm{b}}$, Abdul Nasir Laghari ${ }^{\mathrm{a}}$, \\ Hafiz Usama Imad ${ }^{\mathrm{b}}$, Shadab Noor Bhangwar ${ }^{\mathrm{a}}$ \\ ${ }^{a}$ Civil Engineering Department, QUEST University, Nawabshah. 67480, Pakistan. \\ ${ }^{b}$ Civil Engineering Department, ISRA University, Hyderabad, 71000-313, Pakistan.
}

Received 04 July 2018; Accepted 03 October 2018

\begin{abstract}
There is a philosophy in the construction industry to reduce the cost of a project by reducing construction waste and improving productivity. With lower expenses, lean construction emphasizes the cost of the project at a minimum cost. Globally, the philosophy has gained a wide range of popularity in the construction sector. The Lean Construction has helped practitioners with several tools and techniques to implement at different stages of a construction project. Following global trends, this study has investigated lean practices in Pakistan. With the potential advantages experienced by its implementation in Pakistan's construction projects and the level of implementation of various types of tools and techniques has been analyzed. To achieve the goal, the study had tried to capture construction projects in which four shareholders are being represented, which are clients, consultants, contractors and material suppliers. Overall 34 completed questionnaires were collected and then analyzed. The results of the analysis have indicated that pull approach, standard of work, time consuming, visualization tools, the integrated project delivery methods and the quality failure in safe limits are common lean techniques which are being implemented to the local construction industry. While there are major benefits of waste reduction, client satisfaction, better communication, visual control and proper task management to build appropriate work are the key benefits of lean construction.
\end{abstract}

Keywords: Lean Construction; Lean Tools and Techniques; Lean Benefits; Waste Reduction; Pakistan.

\section{Introduction}

The construction industry is a growing industry on a global level [1]. Fundamental part of economy of many parts of the world depends upon this industry. The $70 \%$ growth of this industry was forecasted by the 'Construction 2025' industrial strategy report published by UK Government in between 2013 and 2025. Several threats as environmental pollution, waste production and energy consumption are however associated with this industry [2]. Besides this, managerial issues, escalations, time and cost overruns are always being intimidations to this trade. Lean Construction, being an emerging solution to this menace is briefly discussed in context of Pakistan in this study.

Implementation of lean techniques at the operational level, integrated delivery stages, strategic decision, leadership decisions, transformational change, and at the site for management of construction and other utilities is defined as lean construction [3]. Lean construction has been an important topic amongst researchers all over the world and is considered as an approach or concept that should be introduced, specifically to increase productivity by reducing waste in the construction process. As stated by [4], Lean construction (LC) as a philosophy and a set of principles was introduced in

* Corresponding author: aftabm78@hotmail.com

http://dx.doi.org/10.28991/cej-03091162

$>$ This is an open access article under the CC-BY license (https://creativecommons.org/licenses/by/4.0/).

(C) Authors retain all copyrights. 
construction to maximize customers' value through waste reduction and continuous improvement. Literature has many case studies describing the effective application of lean construction on real projects. According to [5], From such case studies, the advantages of applying lean were visible, as projects completed within the budget and ahead of targeted schedule (i.e., three weeks earlier than the completion time); the relationship between subcontractor and the main general contractor was improved, comparatively fewer injuries and improved safety standards were observed. Reference [6] reported a $25 \%$ reduction in construction time, an increase in client satisfaction, and a decrease in the overall project cost. Reference [7] showed that the project construction time was reduced by $20 \%$ to $30 \%$ and the cost was reduced by $5 \%$ to $12 \%$. Similarly, [8] presented the beginning of a Lean journey of a small-sized company in Fortaleza/Brazil and found that results achieved in the case study were, project's favorable cash flow, incentives given to early completion of tasks, high level of repetitiveness, use of actual productivity vs. planned to re-schedule the project.

Though traditional approach to Construction management also focuses on sustainability, quality, cost and time but lean construction technique expands this to minimization of environmental degradation, social, contextual and cultural consideration, minimal resource depletion and way to build a health built environment [9-10].

Lean construction approach tries to manage and improve construction processes with minimum cost and maximum value by considering customer needs [11]. Lean construction concept is keen to reduce uncertainty and variability in the execution of project plans. The application of lean in the construction industry has been evolving in the past two decades and many new techniques have been observed since then. Among such techniques, some are practical and are in practice, while many are still in their theoretical development phase and require deep computer programming skills [12]. However, many lean construction tools and techniques are still in an embryonic state, lean construction techniques are gaining popularity because they can affect the bottom line of projects [13]. The absence of suitable tools, improvement, and performance of a lean project program is not possible, which may further result in poor decisions [12].

The traditional approach to construction project management focuses on cost, time and quality objectives, 'sustainability in architecture and construction' expands on these criteria to include minimization of environmental degradation, minimization of resource depletion, contextual, social and cultural consideration and creating a healthy built environment.

There has been very little experimental and theoretical research on lean construction in Pakistan. Therefore, there is a necessity of quantitative research that concentrates on the identification of the status of level of Implementation of Lean Tools and benefits of lean construction for construction projects. Hence, this study aims to assess the current status of lean construction management and its benefits and the tools used to minimize waste in the Construction industry of Pakistan. However, the scope of the data collection was limited to the construction projects carried out in the city of Karachi only. This study focused on identifying the level of execution of various lean tools \&techniques and assesses several benefits achieved by using lean construction.

\section{Literature Review}

A variety of methods are being implemented by researchers to minimize waste amount in construction Industry. Lean construction Approach is one of these methods applied for waste reduction. Lean Construction is a new form of project management applied over the world. Although construction is still being developed, its general principles, techniques, and tools can be applied. One of the basic concepts of thinking of lack of waste is the lean concept. Generally, project managers imagine 'Waste' as a physical waste but, lean concept assumes several other factors hidden in construction process as waste (such as non-valued extra activity and waiting time) [14].

It is certain that lean is the next generation of the construction industry, aims at reducing many fundamental problems, e.g., time delays. Reference [15] has reported loss of almost $57 \%$ of the productive time in most of the construction projects; that further beacons the dire need of further research. For this purpose, many researchers studied the lean construction tools and techniques which can be implemented in the construction industry. Such as, [12] presented 30 new lean tools focusing construction projects Last Planner System (LPS) and Concurrent Engineering and Daily Huddle Meetings. Similarly, [16] also discussed some lean tools and techniques which were just-in-time JIT, Last planner, Automation (Jikoda), Poka-yoke, single-minute exchange devices SMED, Kaizen, five S's, increased visualization , First-run studies, PDCA plan, do, check, and act, huddle meetings and Fail-Safe for Quality. [17] has highlighted several achievements using this technique, such as improved corporate image and sustainable competitive advantage, improved process flow and productivity, improvement in environmental quality and increased compliance with customer ' $\mathrm{s}$ expectations and so on.

There are many more such examples in the literature, some past research papers were studied and 20 lean tools and techniques were mapped with the highest frequency of 15 as shown in Table 1. 
Table 1. Materials of ECC and PCC

\begin{tabular}{|c|c|c|}
\hline S. No & Lean Tools and Techniques & References \\
\hline 1 & $5 \mathrm{~S}^{\prime} \mathrm{s}$ & [20], [12], [34], [35], [18], [25], [21] \\
\hline 2 & Concurrent Engineering & {$[20],[12],[22]$} \\
\hline 3 & Creative Thinking & {$[122,[4],[21]$} \\
\hline 4 & Daily Huddle Meetings & [20], [35], [21] \\
\hline 5 & Fail Safe For Quality & {$[12],[36],[35]$} \\
\hline 6 & First Run Studies & [20], [8], [36], [21] \\
\hline 7 & Increased Visualization & {$[12],[35],[35],[24],[21],[36]$} \\
\hline 8 & Integrated Project Delivery & [22] \\
\hline 9 & Just In Time (JIT) & {$[20],[8],[12],[11],[4],[37],[36]$} \\
\hline 10 & Kaizen(continuous Improvement) & [12], [21] \\
\hline 11 & Last Planner & {$[20],[8],[12],[38],[39],[3],[36],[24]$} \\
\hline 12 & One-Piece Flow & [22] \\
\hline 13 & Poka-Yoke & {$[12],[21]$} \\
\hline 14 & Pull Approach & {$[22],[36]$} \\
\hline 15 & Re-engineering & [12], [4] \\
\hline 16 & The Kanban System & [12] \\
\hline 17 & Total Productive Maintenance & [4] \\
\hline 18 & Total Quality Management & [4] \\
\hline 19 & Value Stream Mapping & {$[20],[12]$} \\
\hline 20 & work standardization & {$[20],[12]$} \\
\hline
\end{tabular}

\subsection{The Five Steps Plan (5s) Process}

The five-step plan (5s), also known as the Visual Work Place, is a technique associated with inventory that focuses a designated place for each material that is to be used on the site. This has process has 5 level of implementation, which can significantly reduce the loss of resources [18].

- Sort (Seiri): Separating material by reference and placing materials and tools close to the work areas with consideration of safety and removing unnecessary items from site location.

- Straighten or set in order (Seiton): Piling materials in a regular pattern and placing tools in gang boxes. Keeping important materials nearby for improving efficiency.

- Shine (Seitso): Cleaning and looking for ways of cleaning and organizing job site and construction equipment, because cleaning is a regular activity.

- Standardize (Seiketsu): Maintaining and monitoring the first three categories to implement standardized methods for improving efficiency.

- Sustain (Shitsuke): Sticking to the rules and regulations for long-term operation.

\subsection{The Five Steps Plan (5s) Process}

These techniques include various tasks of multiple disciplinary teams for improving product engineering cycles for performance, quality, and functionality [19-20].

\subsection{Creative Thinking}

Creative thinking offers continuous improvement through feedback and supports the continual improvement of a production line's daily tasks [13]. 


\subsection{Daily Huddle Meetings}

This technique is used for communicating and for daily meeting procedure of the project team to achieve workers involvement. With project awareness and problem-solving contribution alongside some training that is given by different tools, the satisfaction of job (sense of growth, self-esteem,) will increase [20].

\subsection{Fail Safe for Quality}

This technique depends on the generation of concepts which alert for possible defects. This is almost the same as Poka-Yoke techniques but it can be extended to safety as well. However, the concentration in safety is on possible hazards rather than possible defects, and it is identified with the risk assessment technique. It requires an action plan that avoids bad outcomes [12].

\subsection{First Run Studies}

First-run studies are utilized to remodel important task [22]. Operations are scrutinized thoroughly, bringing ideas and suggestions to explore the alternative of doing the task. The PDCA (plan, do, check, and act) cycle is used to build up the first-run study [23].

\subsection{Increased Visualization}

Visual control is considered a prerequisite for continuous improvement and process control. It includes posting signs for safety, hazards, schedules, and quality standards. The purpose of increased visualization is communicating key information effectively to the workforce by posting various signs and labels around the construction area [24].

\subsection{Integrated Project Delivery}

"A project delivery approach that integrates people, systems, business structures, and practices into a process that collaboratively harnesses the talents and insights of all project participants to optimize project results, increase value to the owner, reduce waste, and maximize efficiency through all phases of design, fabrication, and construction" [25].

\subsection{Just In Time (JIT)}

This technique aims mainly at reducing flow times within a production as well as response times from suppliers and to end users. In any case, JIT is a way of thinking, working and managing to eliminate wastes in processes [12].

\subsection{Kaizen (Continuous Improvement)}

This is Japanese business philosophy for continuous improvement [12]. This is an approach that seeks to create an environment in which responsibilities are assigned to each worker and also encourage and motivate the workers to identify loopholes to improve quality and efficiency through the elimination of waste.

\subsection{The Last Planner System (LPS)}

The Last Planner System (LPS) is one of the tools used in LC which produces anticipated and dependable workflow and fast learning in programming, design, construction, and commissioning of projects [23].

\subsection{One-Piece Flow}

One-Piece Flow system produces many products in medium volumes; on equipment arranged in cells in which material flow is regular and paced by a cycle time; and provides high levels of the flexibility and innovativeness outputs (like the batch flow system) and high levels of the cost and quality outputs [25].

\subsection{Poka-Yoke}

Poka-yoke is a Japanese word which can be defined as "error-proofing" [26]. Poka-yoke devices were introduced by Shingo as new elements in order to avoid defective parts from flowing through the process. It is a lean tool that engages all forms of activities and devices that could avoid an error from happening [23].

\subsection{Pull Approach}

A tool that strengthens our current scheduling process by helping risk management through detailed collaborative planning and continuous improvement. Pull Planning, in simplest terms, is a technique that is used as part of the Last Planner System to develop a coordinated plan for one phase of a project. However, with practice, Pull approach will become much more. 


\subsection{Re-Engineering}

In re-engineering the whole workflow for each activity/process is redesign considering constraints, variances nonvalue activities and then taking the appropriate solution to remove or minimize these to make a uniform workflow. Reengineering can be used from design phase to final execution phase by defining the value of each step or process.

\subsection{The Kanban System}

This is a Japanese word which literally means "billboard or signboard". It is an information control process which regulates the movements or flow of resources so that parts and supplies are ordered and released as they are needed [12].

\subsection{Total Productive Maintenance}

TPM is a powerful program for planning and achieving minimal machine downtime. The aim is to divert from fixing breakdowns. For this purpose, Machine operators take far greater responsibilities of monitoring the function of machines and warning the constructors regarding the multifunction of machines.

\subsection{Total Quality Management}

Total Quality Management uses a combination of Statistical process control and problem-solving teams to improve process capability and ensure that external factors do not negatively affect the process driving it out of control [27, 28].

\subsection{Value Stream Mapping}

A technique for visually analyzing, documenting and improving the flow of a process in a way that highlights improvement opportunities [12].

\subsection{Work Standardization}

Standardized work is one of the most powerful but least used lean tools. By documenting the current best practice, standardized work forms the baseline for kaizen or continuous improvement. As the standard is improved, the new standard becomes the baseline for further improvements, and so on. Improving standardized work is a never-ending process.

Recently, development of lean construction has shown an improved development of the construction industry. Certain complications are observed due to the unpredictable nature of the construction process, to fully implement this technique. However much better and sustainable results are obtained by use of this philosophy [29]. In recent times, the lean construction approach has shown to be a viable means of creating value and minimizing waste on construction projects [30].

\section{Methodology}

This research is carried out through quantitative research method involving a questionnaire survey for data collection. Survey was conducted through interviews, posts, by hand and through Emails to professional respondents (client, consultant, contractors and material suppliers) and were asked to fill the questionnaire forms in order to identify the status of level of implementation of Lean Construction Tools \& Techniques in Construction Industry of Pakistan, and to identify the benefits achieved by Lean Construction tools.

The questionnaire was classified into a close form or restricted type. Closed questionnaires often require short responses in the form of Yes or No, Agree or Disagree, Important or Not Important, etc. Closed-ended questions are easy to ask and quick to answer, they require no writing by either respondent or interviewer, and their analysis is straightforward [31].

The questionnaire consisted of three parts which are Part 1, Part 2 and Part 3. Part 1 is focused on Respondent Demography which is seeking respondent's information such as education, years of experience, position in the organization and also the type of their organization. Part 2 of the questionnaire is to assess the current status of tools used in the construction industry, where 20 tools and techniques were enlisted. While part 3 is on benefits achieved from lean construction tools and techniques, where 21 different types of benefits of lean construction were given.

A total of 100 questionnaires were distributed randomly in many construction Companies of Pakistan and 34 completed questionnaire sets were received back which are analyzed using the weighted average method. 5 scale Likert's Scale was used to rank the importance of the factors identified in the questionnaires, which are then grouped and categorized as per relative weight or weighted average. The analysis is done by using statistical software package SPSS and MS Excel [32]. 


\section{Results and Discussion}

This section presents the results and discussions of analysis for the data collected through a questionnaire survey. The questionnaire survey was aimed to identify the current status and benefits of Lean Construction Management tools and techniques in Pakistan.

\subsection{Characteristics of Respondents}

The Table 2 shows that majority of respondents are consultants i.e. 13 out of 34 with a percentage of $38.2 \%$ of these, a significant number of contractors i.e. 12 of 34 with the percentage of $35.3 \%$, Clients are 5 with the percentage of $14.7 \%$. And 4 out of 34 are material suppliers with the percentage of $11.8 \%$.

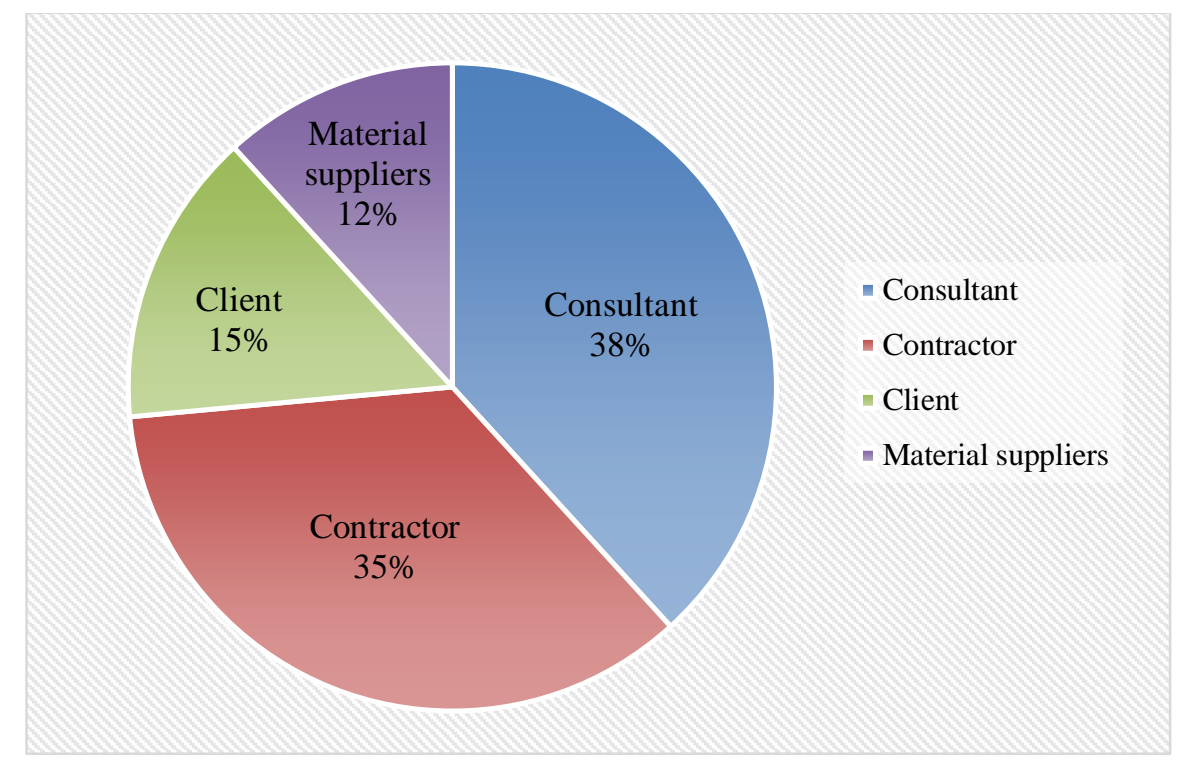

Figure 1. Characteristics of Respondents

\subsection{Respondent's Experience}

Table 3, shows a significant number i.e. 13 out of 34 with $38.2 \%$ respondents have experience within 5 years of handling large projects, the respondents having experience $6-10$ years are 7 with $20.6 \%$, the 4 respondents with $11.8 \%$ having experience $11-15$ years, and 10 respondents with $29.4 \%$ had experience over 15 years.

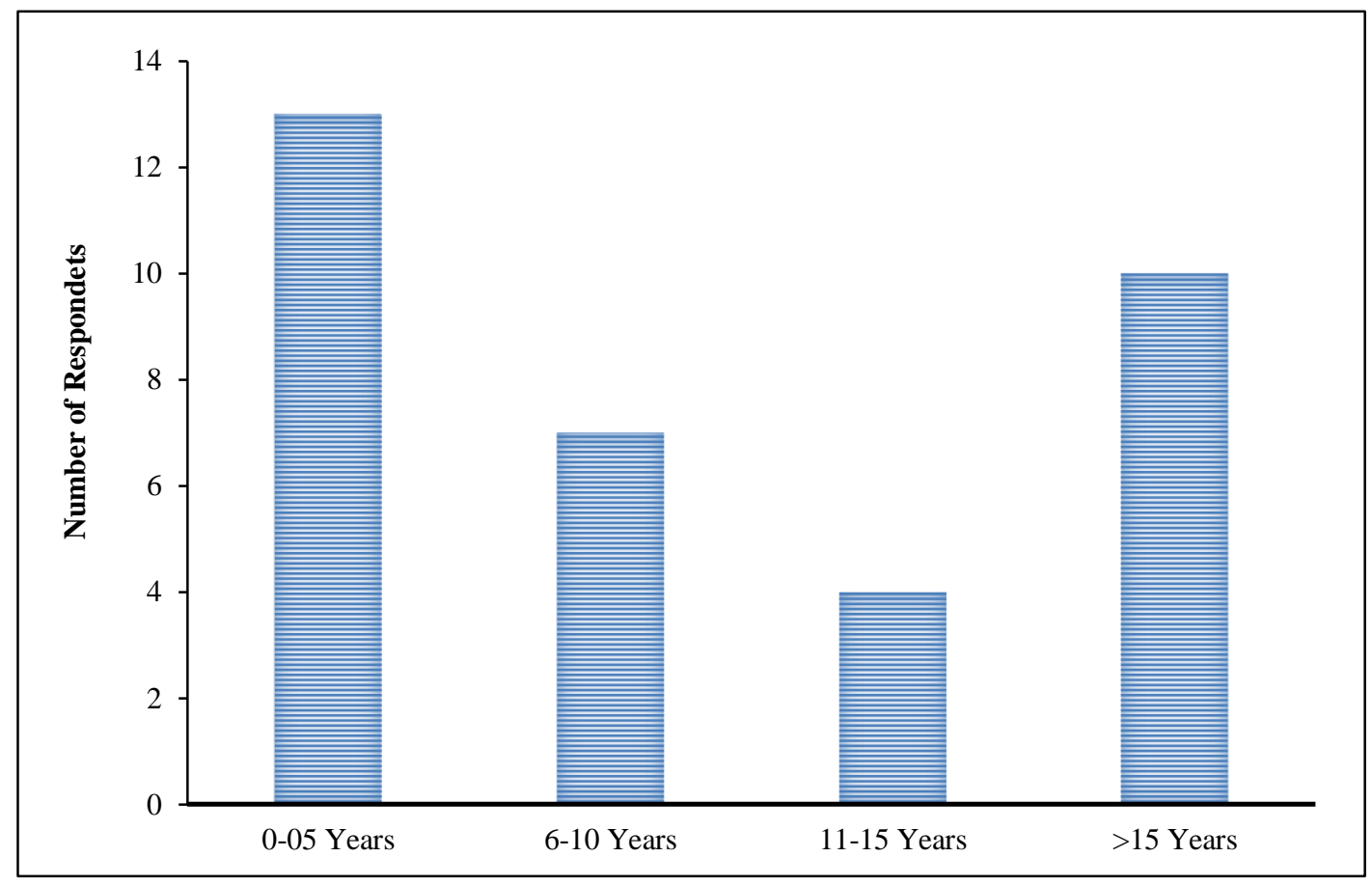

Figure 2. Experience of Respondents 


\subsection{Cost of Project}

The table 4, shows that 1 projects are of the <RS $20 \mathrm{M}$, with a percentage $2.9 \%$, likewise between $20 \mathrm{M}-50 \mathrm{M}$ are 2 with $5.9 \%$, RS 50 M- $150 \mathrm{M}$ are 5 projects with $14.7 \%$. RS $150 \mathrm{M}-400 \mathrm{M}$ are 11 with $32.4 \%$ RS $800 \mathrm{M}-1800 \mathrm{M}$ are 7 with $20.6 \%$, RS 1800 M- $3000 \mathrm{M}$ are 2 with $5.9 \%$ and > RS $3000 \mathrm{M}$ are 6 with $17.6 \%$.

Table 4. Cost of Projects

\begin{tabular}{ccc}
\hline Cost of project & Frequency & Percent \\
\hline$<20 \mathrm{M}$ & 1 & 2.9 \\
$20 \mathrm{M}-50 \mathrm{M}$ & 2 & 5.9 \\
$50 \mathrm{M}-150 \mathrm{M}$ & 5 & 14.7 \\
$150 \mathrm{M}-400 \mathrm{M}$ & 11 & 32.4 \\
$800 \mathrm{M}-1800 \mathrm{M}$ & 7 & 20.6 \\
$1800 \mathrm{M}-3000 \mathrm{M}$ & 2 & 5.9 \\
$>3000 \mathrm{M}$ & 6 & 17.6 \\
Total & 34 & 100.0 \\
\hline
\end{tabular}

\subsection{Tools and Techniques}

From questionnaire survey, respondents perspective were collected towards implementation of lean tools, respondents were asked to rate the implementation of lean construction tool with respect to their implementation on a Likert point scale ranging from 1 to 5, where 1 = Not Implemented, 2 = Rarely Implemented, 3= Sometime Implemented, 4 = Oftenly Implemented and 5 = Mostly Implemented. 20 tools of lean construction were examined through literature mapping from past research papers towards their implementation. Each tool shows respondents frequency with respect to their level of implementation. Then the collected data is analyzed by Weighted Analysis.

Weighted opinion averages of each tool of lean construction were determined to assess their perceived significance. The average weighted perceived significance was then computed using the formula adapted from [33].

$$
W A=\frac{1}{5} \times \frac{\sum_{1}^{5} \mathrm{~F}_{\mathrm{i}} \mathrm{R}_{\mathrm{i}}}{\sum_{1}^{5} \mathrm{~F}_{\mathrm{i}}} \times 100
$$

Where WA is the average weighted perceived significance; $R_{i}$ is the response type on the Likert scale, $\mathrm{i}$ ranging from 1 to 5 on the Likert scale; $F_{i}$ is the frequency or total number of respondents choosing response type i on the Likert scale, with i ranging from 1 to 5 as earlier described.

As an example, WA, the average weighted perceived significance was computed as follows:

$$
W A=\frac{1}{5} \times\left\{\frac{\left(\mathrm{F}_{1} \times R_{1}+\mathrm{F}_{2} \times R_{2}+\mathrm{F}_{3} \times R_{3}+\mathrm{F}_{4} \times R_{4}+\mathrm{F}_{5} \times R_{5}\right)}{\left(\mathrm{F}_{1}+\mathrm{F}_{2}+\mathrm{F}_{3}+\mathrm{F}_{4}+\mathrm{F}_{5}\right)}\right\} \times 100
$$

It is noteworthy that the possible values of average weighted perceived significance, WA, ranged from $25 \%$ to $100 \%$ because each factor identified through literature or interviews had some level of significance that would not amount to zero. The factors whose WA score was $50 \%$ and above were categorized as major tools which are mostly implemented in the construction industry of Pakistan.

By applying the weighted average formula in the collected data, the result is shown in following figures. 


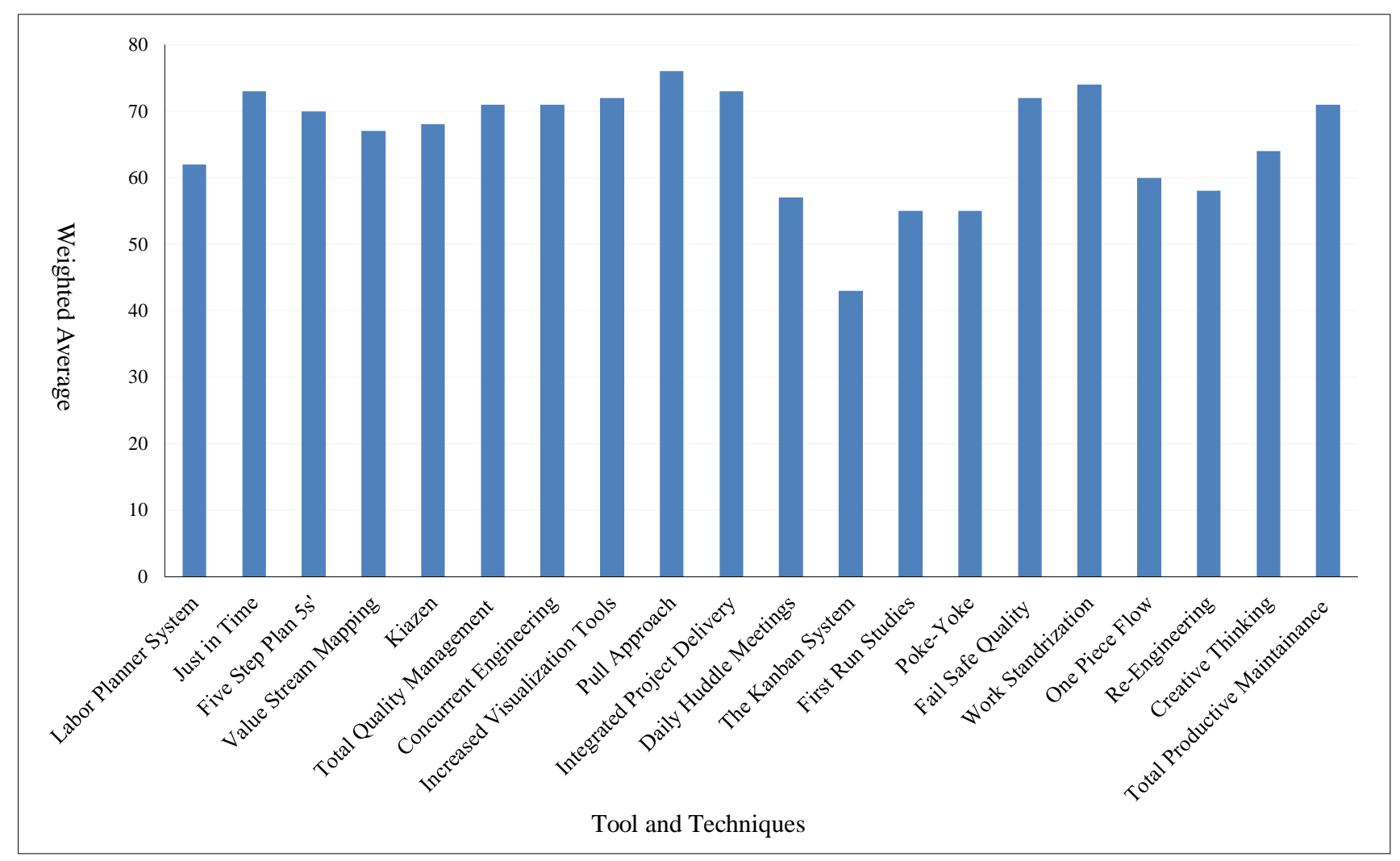

Figure 3. Tool and Techniques

\subsection{Benefits of Lean}

Data collected from the 3rd part of the questionnaire (where respondents were required to fill short responses in the form of Yes or No) were analyzed by software SPSS V.25. The results are shown in the following Table 5.

Table 5. Benefits of Lean Tools and Techniques

\begin{tabular}{ccccc}
\hline S. No & Benefits & Yes & No & Total \\
\hline 1 & Reduce Project Duration & $21(61.8)$ & $13(38.2)$ & $34(100)$ \\
2 & Reduction in waste & $30(88.2)$ & $4(11.8)$ & $34(100)$ \\
3 & Smooth Work flow & $25(73.5)$ & $9(26.5)$ & $34(100)$ \\
4 & Visual control & $28(82.4)$ & $6(17.6)$ & $34(100)$ \\
5 & Improved safety & $25(73.5)$ & $9(26.5)$ & $34(100)$ \\
6 & Improve Project Quality & $24(70.6)$ & $10(29.4)$ & $34(100)$ \\
7 & Client's Satisfaction & $29(85.3)$ & $5(14.7)$ & $34(100)$ \\
8 & Improved flexibility & $21(61.8)$ & $13(38.2)$ & $34(100)$ \\
9 & Proper Scheduling & $26(76.5)$ & $8(23.5)$ & $34(100)$ \\
10 & Defects reduction & $19(55.9)$ & $15(44.1)$ & $34(100)$ \\
11 & Standardizing work & $22(64.7)$ & $12(35.2)$ & $34(100)$ \\
12 & Simplifying Work & $22(64.7)$ & $12(35.2)$ & $34(100)$ \\
13 & Reduction in cost & $20(58.8)$ & $14(41.2)$ & $34(100)$ \\
14 & Proper Estimation & $26(76.5)$ & $8(23.5)$ & $34(100)$ \\
15 & Greater Profit & $15(44.1)$ & $19(55.9)$ & $34(100)$ \\
16 & Improved Communication & $29(85.3)$ & $5(14.7)$ & $34(100)$ \\
17 & Minimize Inventory & $17(50.00$ & $17(55.0)$ & $34(100)$ \\
18 & Control Budget & $24(70.6)$ & $10(29.4)$ & $34(100)$ \\
19 & Proper Task Management & $28(82.4)$ & $6(17.6)$ & $34(100)$ \\
20 & Simplify Data organizing & $23(67.6)$ & $11(32.4)$ & $34(100)$ \\
21 & Stress Free Working Environment & $27(79.4)$ & $7(20.6)$ & $34(100)$ \\
\hline & & & &
\end{tabular}


Results shows that Reduction in waste is on 1st rank, Client's Satisfaction and Improved Communication are on 2nd rank and Proper Task Management and Visual controls are on 3rd rank.

\section{Conclusion}

Results show that Reduction in waste is on 1st rank, Client's Satisfaction and Improved Communication are on 2nd rank and Proper Task Management and Visual controls are on 3rd rank. Waste is extra activities that consume time with non-value added activities that are the main reason of extra project cost rather than their actual budget that's why Profit content is greater in lean construction management techniques than the traditional methods of construction management.

From the results, it is clear that almost all lean tools and techniques are used in construction industry, but due to lack of supports from construction organizations and fewer researches in lean construction, they are not fully implemented as they are functioned. Many respondents using these techniques are not fully aware of their specified functions for that they are made. Although still, Lean construction is in its beginning stages so large efforts are required to implement Lean techniques properly.

\section{Limitation of Study}

Limitations of the study are related with respondents, the more the respondents, more accurate results. The data collected were gathered keeping in view all the sections of the construction projects such as design, structural, material, survey, and management section, so all the respondents were not expected to have full understanding of every section because every respondent will be expert in the factors which he daily exercises only that is why he will be giving accurate response to those factors which are related to his section.

\section{References}

[1] Oyedele, L., Regan, M., Meding, J., Ahmed, A., Ebohon, O., and Elnokaly, A., "Reducing waste to landfill in the UK: identifying impediments and critical solutions", World Journal of Science, Technology and Sustainable Development, 10(2), pp. 31-142, 2013. https://doi.org/10.1108/20425941311323136.

[2] Sarhan, S., Elnokaly, A., Pasquire, C., and Pretlove, S., "Lean Construction and Sustainability through IGLC Community: A Critical Systematic Review of 25 Years of Experience", In: Proc. 26th Annual Conference of the International. Group for Lean Construction (IGLC), González, V.A. (ed.), Chennai, India, pp. 1-10, 2018. DOI: https://doi.org/10.24928/2018/0274.

[3] Tezel, A., Koskela, L., \& Aziz, Z., "Lean thinking in the highways construction sector: motivation, implementation and barriers", Production Planning \& Control, 29(3), pp. 247-269, 2018. doi:10.1080/09537287.2017.1412522

[4] Koskela, L. “Application of the new production philosophy to construction”, Stanford: Stanford University, Vol. 72, pp. 1-81, 1992.

[5] Salem, O., Solomon, J., Genaidy, A., \& Luegring, M., "Site implementation and assessment of lean construction techniques", Lean Construction Journal, 2(2), pp. 1-21, 2005.

[6] Garnett, N., Jones, D. T., \& Murray, S., "Strategic application of lean thinking”, In Proceedings IGLC, 98, pp. 1-12, 1998.

[7] Conte, A.S.I., \& Gransberg, D.D., "Lean Construction: From Theory to Practice," 2001 Transactions, AACE, Int'1, Pittsburgh, Pennsylvania, June 2001 pp CSC10.01-CSC10.05

[8] Mota, B.P. Mota, R.R \& Alves, T.D.C., "Implementing Lean Construction Concepts in a Residential Project” In: Tzortzopoulos, P. \& Kagioglou, M., 16th Annual Conference of the International Group for Lean Construction. Manchester, UK, 16-18 Jul 2008. pp. 251-257, 2008.

[9] Elnokaly, A., and Vyas, M., "A cross case investigation of sustainability assessment tools of the LEED, BREEAM and GRIHA”, $\mathrm{n}$ : Transitions to sustainable societies: Designing research and policies for changing lifestyles and communities (IAPS 23 Conference), 24 - 27 June 2014, Timisoara, Romania, pp. 1-11, 2014.

[10] Sarhan, S., Pasquire, C., and King, A., "The concept of institutional waste within the construction industry: a potential theoretical framework", Lean Construction Journal, pp.12-24, 2017.

[11] Koskela, L., Howell, G., Ballard, G., \& Tommelein, I.. “The foundations of lean construction”, Design and construction: Building in value, pp. 211-226, 2002.

[12] Ansah, R. H., Sorooshian, S., Mustafa, S. B., \& Duvvuru, G, "Lean Construction Tools." Proceedings of the 2016 International Conference on Industrial Engineering and Operations Management Detroit, Michigan, USA, September 23-25, 2016.

[13] Salem, O., Solomon, J., Genaidy, A., \& Luegring, M., "Site implementation and assessment of lean construction techniques", Lean Construction Journal, 2(2), pp. 1-21, 2005.

[14] Nikakhtar, A., Hosseini, A. A., Wong, K. Y., \& Zavichi, A., "Application of lean construction principles to reduce construction process waste using computer simulation: a case study", International Journal of Services and Operations Management, 20(4), pp. 461-480, 2016. https://doi.org/10.1504/IJSOM.2015.068528.

[15] Ansah, R. H., Sorooshian, S., \& Mustafa, S. B., "Lean construction: an effective approach for project management. ARPN", Journal of Engineering and Applied Sciences, 11(3), pp. 1607-1612, 2016. 
[16] Schweikhart, S. A., \& Dembe, A. E., "The applicability of Lean and Six Sigma techniques to clinical and translational research," Journal of Investigative Medicine, 57(7), pp. 748-755, 2009. http://dx.doi.org/10.2310/JIM.0b013e3181b91b3a.

[17] Ogunbiyi, O., Goulding, J. S., \& Oladapo, A., "An empirical study of the impact of lean construction techniques on sustainable construction in the UK", Construction innovation, 14(1), pp. 88-107, 2014. https://doi.org/10.1108/CI-08-2012-0045.

[18] Ingle, A., \& Waghmare, P. A. P., "Advances in Construction: Lean Construction for Productivity enhancement and waste minimization", International Journal of Engineering and Applied Science, 2(11), pp. 19-23, 2015.

[19] Aziz, R. F., \& Hafez, S. M.“Applying lean thinking in construction and performance improvement”, Alexandria Engineering Journal, 52(4), pp. 679-695, 2013. https://doi.org/10.1016/j.aej.2013.04.008.

[20] Rahman, H. A., Wang, C., \& Lim, I. Y. W. "Waste processing framework for non-value-adding activities using lean construction”, Journal of Frontiers in Construction engineering, 1(1), 8-13, 2012.

[21] Salem, O., Solomon, J., Genaidy, A., \& Minkarah, I.. "Lean construction: From theory to implementation", Journal of management in engineering, 22(4), pp. 168-175, 2006. https://doi.org/10.1061/(ASCE)0742-597X(2006)22:4(168).

[22] Ballard, G., \& Howell, G. "Implementing lean construction: improving downstream performance”, Lean construction, 111-125, 1997

[23] Wan Muhammad, Wan Mohd Nurdden, Zulhabri Ismail, and Ahmad Ezanee Hashim. "Exploring Lean Construction Components for Malaysian Construction Industry." 2013 IEEE Business Engineering and Industrial Applications Colloquium (BEIAC) (April 2013). doi:10.1109/beiac.2013.6560091.

[24] Awada, M. A., Lakkis, B. S., Doughan, A. R., \& Hamzeh, F. R., "Influence of Lean Concepts on Safety in the Lebanese Construction Industry." In: Proc. 24th Ann. Conf. of the Int'l. Group for Lean Construction, Boston, MA, USA, sect.11 pp. 63-72, 2016.

[25] Kent, D. C., \& Becerik-Gerber, B. "Understanding construction industry experience and attitudes toward integrated project delivery", Journal of construction engineering and management, 136(8), pp. 815-825, 2010. https://doi.org/10.1061/(ASCE)CO.19437862.0000188

[26] Mehany, M. S. H. M. Lean Construction Principles Past and Present-A Business Model Consistency. In ASC Proceedings of the 51st Annual Conference, 2015.

[27] Akhund, M. A., Khahro, S. H., Ali, T. H., \& Memon, N. A., "ISO 9001:2008: A Factorial Analysis of Its Advantages and Implementation For Construction Firms", International Journal of Civil Engineering and Technology, 8(6), pp. 969-976, 2017.

[28] Akhund, M. A., Khahro, S. H., Siddiqui, F. H., Khoso, A. R., "Adaptability of ISO quality standards in construction industry”, Journal of Engineering and Applied Sciences, 13(4), pp. 926-9, 2018. DOI: 10.3923/jeasci.2018.926.929.

[29] Ruan, X., Ochieng, D. E., Zuofa, T., \& Yang, M., “An Appraisal of Lean Construction Project Delivery: Application of Lean Construction", July 2016.

[30] Daniel, E., \& Pasquire, C., "Creating social value within the delivery of construction projects: the role of lean approach", Engineering, Construction and Architectural Management, (2018).

[31] Naoum, Shamil. "Dissertation Research and Writing for Construction Students" (May 23, 2012). doi:10.4324/9780080467047.

[32] Akhund, M. A., Khoso, A. R., Memon, U., \& Khahro, S. H., "Time Overrun in Construction Projects of Developing Countries", Imperial Journal of Interdisciplinary Research, 3(5), pp. 1-6, 2017.

[33] Kaliba, C., Muya, M., \& Mumba, K. "Cost escalation and schedule delays in road construction projects in Zambia", International journal of project management, 27(5), pp. 522-531, 2009. https://doi.org/10.1016/j.ijproman.2008.07.003.

[34] Enshassi, A., \& Zaiter. M. A. "Implementation of Lean Tools on Safety in Construction Projects in Palestine", In 22nd annual conference Proceedings IGLC, Oslo, Norway, pp. 1205-1218, 2014.

[35] Pan, W., Pan, M. and Chan, S., "Lean construction for improving productivity in the Hong Kong construction industry", Building Journal, pp. 57-61, November 2015.

[36] Ballard, G., Tommelein, I., Koskela, L., \& Howell, G., Lean construction tools and techniques, In Design and Construction, pp. 251-279. Routledge, 2007.

[37] Nakagawa, Y. \& Shimizuz, Y., "Toyota Production System Adopted by Building Construction in Japan”, In Bertelsen, S. \& Formoso, C.T., 12th Annual Conference of the International Group for Lean Construction. Helsingør, Denmark, 3-5 Aug 2004, pp. $1-15,2004$

[38] larcón, L. F., Pavez, I., Diethelm, S., \& Rojo, O., "Preparing contractor organizations for implementing lean construction", In 2nd Specialty Conference on Leadership and Management in Construction, Grand Bahama Island, Bahamas, May 4-6, 2006, pp. 290-309, 2006.

[39] Bertelsen, S. "Lean Construction: Where are we and how to proceed”, Lean Construction Journal, 1(1), pp. 46-69, 2004. 